\title{
Incidence and Assessment of Adverse Drug Reactions at a Tertiary Care Hospital
}

\author{
Pulimi Divya Priyanka ${ }^{1, *}$, T. Vithya ${ }^{1}$, Shobha Rani Rajeev Hiremath ${ }^{1}$ and Shankar Prasad ${ }^{2}$ \\ ${ }^{1}$ Department of Pharmacy Practice, Al Ameen College of Pharmacy, Bangalore, Karnataka, INDIA. \\ ${ }^{2}$ St. Philomena's Hospital, Bangalore, Karnataka, INDIA.
}

Received: 17 October 2019

Accepted: 12 December 2019

*Correspondence to:

Dr. Pulimi Divya Priyanka, PharmD Department of Pharmacy Practice, Al Ameen College of Pharmacy, Bangalore-560027,

Karnataka, INDIA.

Email:divya.pulimi04@gmail.com Copyright: (C) the author(s),publisher and licensee Indian Academy of Pharmacists. This is an open-access article distributed under the terms of the Creative Commons Attribution Non-Commercial License, which permit unrestricted non-commercial use, distribution, and reproduction in any medium, provided the original work is properly cited.

\begin{abstract}
Background: Adverse drug reactions have proved a significant problem in healthcare for decade. Healthcare professionals have a responsibility in use of rational drugs for their patients. Objectives: The aim of the study was to determine the prevalence of ADRs in a tertiary care hospital to determine the most common Therapeutic Class of Drugs causing ADR and to determine the most common Organ system affected by ADR. Methods: The Prospective, observational study was conducted in the wards of St. Philomena's Hospital, Bangalore between January 2016 and August 2016. All In-patients were monitored for ADRs during their admission period. Results: Over the study period of 12 months, a total of 374 ADRs were reported in 600 patients. The ADRs observed were higher in female patients [196 (52.4\%)]. A predominance of gastrointestinal reactions [70 (18.71\%)] was observed. Therapeutic classes of drugs frequently associated with ADRs were antibiotics [84(22.4\%)] followed by antihypertensive agents [63 (16.84\%)] and antidiabetic [37 $(9.89 \%)]$. The most common drugs involved in causing ADRs were Furosemide and Cefoperazone and the most commonly reported ADR was Diarrhoea [28 (7.4.8\%)] followed by Itching $2[9(7.75 \%)]$. Majority of the ADRs [95 $(74.80 \%)$ ] were managed by withdrawing the suspected drug. The causality assessment of the ADRs were carried out using the Naranjo's Scale algorithm and the majority of the ADRs were found to be definite [41 (32\%)]. Conclusion: Continuous monitoring by a clinical pharmacist in hospital setup will reduce the occurrence of $A D R$ and improve the patient safety.
\end{abstract}

Key words: Adverse drug reaction, Pharmacovigilance, Naranjo scale, Causality assessment, Patient safety.

\section{INTRODUCTION}

Adverse drug reactions have a major impact on public health and are major cause of hospital admissions, reducing patient's quality of life and imposing a considerable financial burden on the health care systems. ${ }^{[1]}$

World Health Organization defines an adverse drug reaction (ADR) as "a response to a drug that is noxious and unintended and occurs at doses normally used in man for the prophylaxis, diagnosis or therapy of disease, or for modification of physiological function".

Adverse drug reactions (ADRs) are a major cause of hospital admissions, but recent data on the incidence and clinical characteristics of ADRs which occur following hospital admission, are lacking. The purpose of documenting adverse drug events is to prevent future injuries for patients. New adverse drug reactions are often discovered when drugs are used in larger or in different populations than studied during initial clinical trials. Therefore, documentation and reporting becomes a crucial element in clarifying the side effect profile of a drug. But recent data on the incidence and clinical characteristics of ADRs which occur following hospital admission are lacking. ${ }^{[2]}$

It is clear that adverse drug reactions adversely affect patients quality of life and can also cause patients to lose confidence in healthcare system and reduce the patient therapeutic outcome and medication adherence because of the related ADRs of each medicine that the patient experience. Apart from that there is a significant impact through increase costs of patient care and the potential to lengthen hospital stays.

Primary objective of the study was to determine the prevalence of adverse drug reactions in a tertiary care hospital. Secondary objectives were to determine the most frequent Therapeutic Class of Drugs causing ADR and to determine the most frequent organ system affected by ADR.

\section{METHODOLOGY}

A prospective, observational study was carried out in the wards of St. Philomena's Hospital, Bangalore for a period of 12 months between" January 2018 to December 2018". All In-patients of both genders who experienced an ADR were enrolled for the study, with the approval of Institutional Ethics committee and the consent of the study population.

Study criteria Inclusions: All In-patients of both gender who experienced ADR during their hospital stay.

Exclusions: Patients admitted to hospital due to an ADR.

\section{Data collection}

Data on the reported ADRs were evaluated to understand the pattern of the 


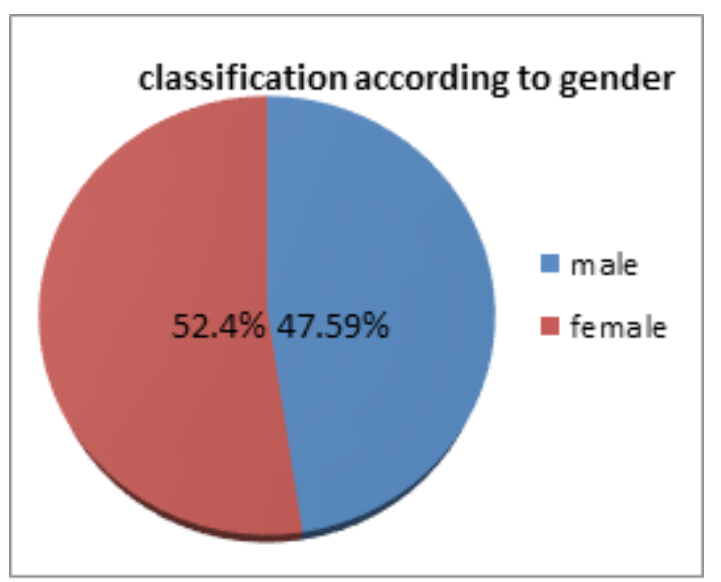

Figure 1: Classification affected according to the gender.

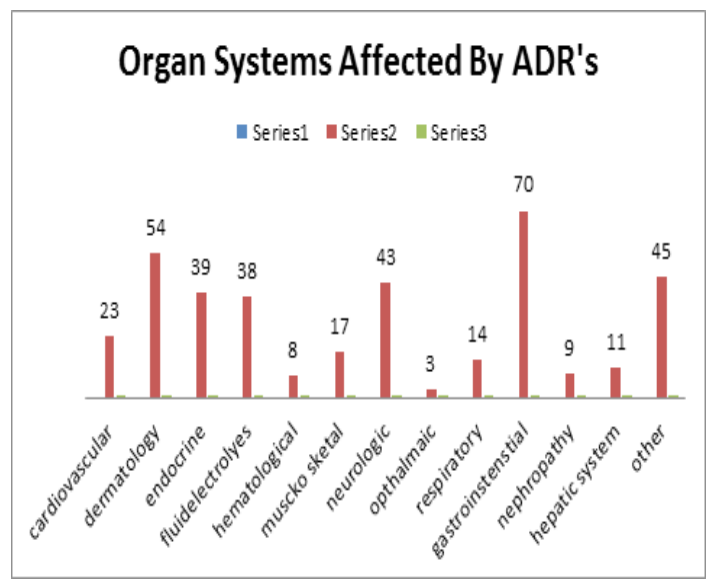

Figure 2: Organ systems affected by ADRs.

ADRs with respect to patient demographic disease, nature of the reactions, characteristics of the drugs involved and outcome of the reactions.

\section{Analysis of ADRs}

The severity of adverse drug reactions was assessed using Naranjo's scale. The Naranjo's causality assessment scale contains a score value $\geq 9$ indicated a definite causal relation between the drug and the ADR; 5-8 as indicated a probable relation; $1-4$ indicated a possible relation and a score of $\leq 0$ indicated an unlikely relation.

\section{RESULTS AND DISCUSSION}

Over the study period of 12 months, a total number of 374 ADRs were reported in 600 patients. ADRs were higher in female patients [196 (52.41\%)]. A predominance of gastro-intestinal reactions [70 (18.71\%)] was observed followed by fluid and electrolytes imbalance [38 (14.423\%)], dermatological reaction [54 (14.43\%)] and neurologic [43 (11.49\%)]. The result of the study was similar to study conducted by Wei Yew W et al. ${ }^{\left[{ }^{[3]}\right.}$ Evans et al. also showed the prevalence of gastrointestinal tract adverse events (abdominal pains, constipation, diarrhoea, nausea and vomiting) was $64 \% .{ }^{[4]}$ Therapeutic classes of drugs frequently associated with ADRs were antibiotics [84 (22.40\%)] followed by antihypertensive agent s $[63(16.84 \%)]$. The most common drugs involved in causing ADRs were Furosemide and Cefoperazone which was similar to the study conducted by Julie Dupouy et al..$^{[5]}$ The most commonly reported ADR was Diarrhoea [28(7.48\%)].

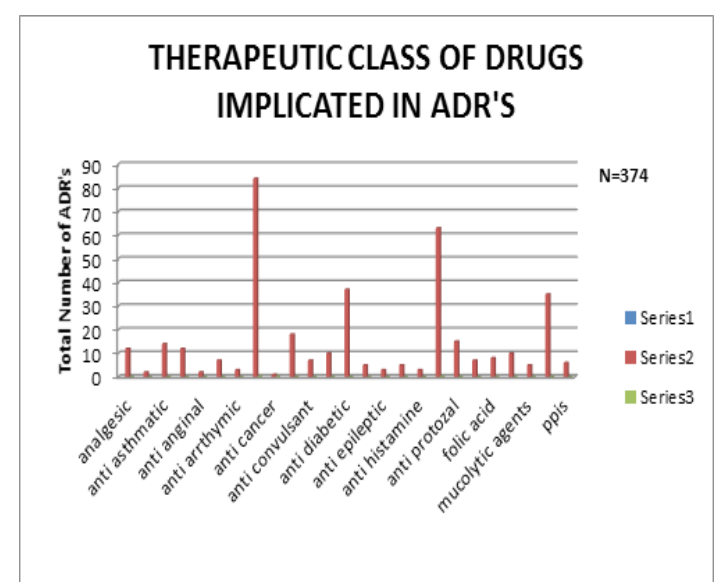

Figure 3: Therapeutic class of drugs implicated in ADRs.

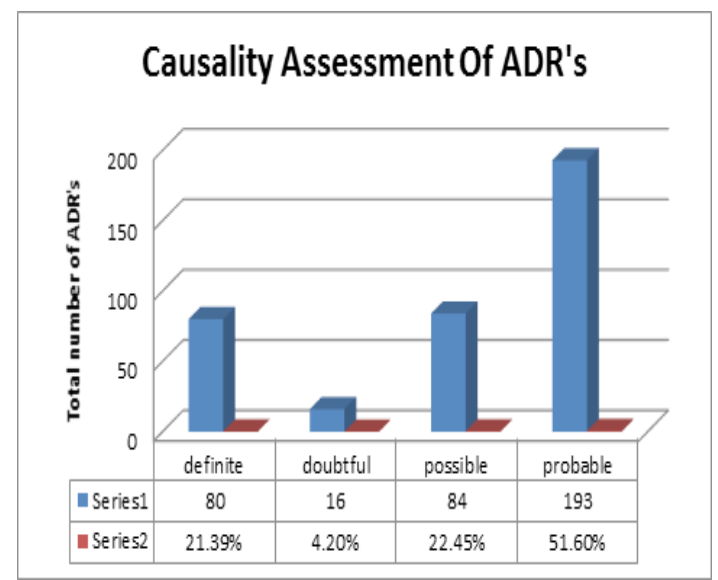

Figure 4: Causality Assessment of ADR's.

Majority of the ADRs [95 (74.80\%)] were managed by withdrawing the suspected drug. The causality assessment of the ADRs were carried out using the Naranjo's Scale algorithm and the majority of the ADRs were found to be definite [41 (32.28\%)]. The result of the studywas different with the study conducted by Renuka et al. ${ }^{[6}$ In which the most common ADRs were found to be probable.

\section{CONCLUSION}

In order to prevent adverse drug reactions and antibiotics resistance, continuous monitoring of medications by a clinical pharmacist in hospital setup will definitely reduce the occurrence of ADR and improve the patient safety.

\section{REFERENCES}

1. Vikas S, Ramesh M, Rani VN, Thennarasu P, Kannan G. Incidence of diuretics induced adverse drug reactions in an intensive cardiac care unit of a tertiary care teaching hospital. Int J Pharm Sci Res. 2017;8(8):3557-62. doi: 10.13040/ IJPSR.0975-8232,8(8):3557-62.

2. Doshi MS, Patel PP, Shah SP, Dikshit RK. Intensive monitoring of adverse drug reactions in hospitalized patients of two medical units at a tertiary care teaching hospital. J Pharmacol Pharmacother. 2012;3(4):308-13.

3. Yew WW, Chan CK, Chau CH, Tam CM, Leung CC, Wong PC, et al. Outcomes of patients with multidrug-resistant pulmonary tuberculosis treated with ofloxacin/ levofloxacin-containing regimens. Chest. 2000;117(3):744-51.

4. Sagwa E, Mantel-Teeuwisse A, Ruswa N, Musasa JP, Pal S, Dhliwayo P, et al. The burden of adverse events during treatment of drug-resistant tuberculosis in 
Priyanka, et al.: Incidence and Assessment of ADRs

Namibia. Southern Med Review. 2012;5(1):6-13.

5. Julie D, Guillaume M, Marie T, Marie E, Agnès S, Jean-Christophe P, et al. Which Adverse Events Are Related to Health Care during Hospitalization in Elderly
Inpatients?. Int J Med Sci. 2013;10(9):1224-30.

6. Renuka CV, Darling C. Retrospective analysis of adverse drug reactions induced by antibiotics in a tertiary care centre. WJPR. 2014;3(10):2277-7105.

Cite this article as: Priyanka PD, Vithya T, Hiremat SRR, Prasad S. Incidence and Assessment of Adverse Drug Reactions at a Tertiary Care Hospital. J Pharm Pract Community Med. 2020;6(1):15-7. 